\title{
Rare Presentation of Intra-Abdominal Testicular Mass: A Case Report
}

\author{
Dr. Govind K Purushothaman ${ }^{1}$, Dr. Shailendra Kumar ${ }^{2}$, Dr. K K Acharya ${ }^{3}$, Dr. Aditya Tripathi ${ }^{4}$, \\ Dr. Abid Raval ${ }^{4}$

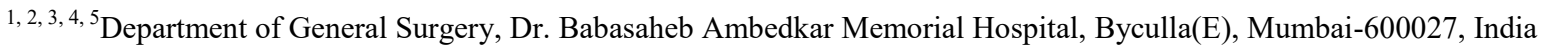

\begin{abstract}
The most common site of undescended testes are high scrotal, canalicular, abdominal and bilateral cryptorchidism. The most common congenital anomaly of genitor-urinary tract in male is encountered in $1 \%$ of boys. In cryptorchid testicles the incidence of testicular cancer is considered to be 3- 48 times greater than general population. Due to measures of the prevention in force, it is uncommon yto find case of tumor in intra-abdominal testicles. An abdominal testis is 4 times more likely to undergo malignant degeneration than an inguinal testis. The cancer of undescended testis usually are picked up in $3^{\text {rd }}$ and $4^{\text {th }}$ decade of life.In this case, we present a rare case of an adult patient with a huge intra-abdominal testicular tumor.
\end{abstract}

Keywords: Cryptorchidism, Testicular cancer, Seminoma, Ectopic Testis, Orchidectomy, Orchidopexy

\section{Introduction}

During fetal development, the testes develop in the abdomen and later descend into the scrotal sac in the third trimester, usually between weeks 28 to 32 . During the descent, it may be arrested anywhere along its tract (cryptorchidism) or may migrate into an abnormal position (ectopic testis). The most common sites of undescended testis are high scrotal, canalicular, abdominal, and bilateral. ${ }^{1}$ Cryptorchidism, the most common congenital anomaly of the genitourinary tract in males, is encountered in $1 \%$ of boys. ${ }^{2}$

In cryptorchid testicles, the incidence of testicular cancer is considered to be 3 to 48 times greater than in the general population. Testicular cancer is developed in $10 \%$ of the cases with undescended testicles. ${ }^{-}$Various tumor markers are available in the form of alpha fetoprotein $(\alpha$-FP), beta human chorionic gonadotrophin ( $\beta$-HCG), lactate dehydrogenase (LDH), and placenta-like alkaline phosphotase (PLAP). They are helpful not only in making the diagnosis but also in formulating a management plan. Their sensitivity and specificity vary according to the type of testicular tumor. ${ }^{4}$

Due to measures of prevention in force, it is uncommon to find cases of tumors in intra-abdominal testicles. This case report presents a new case of an adult patient with an intraabdominal testicular tumor.

\section{Case Report}

A 28-year-old patient, the father of two children, was referred to our hospital (Dr. Babasaheb Ambedkar Memorial Hospital, Byculla, Mumbai). He had complaints of lump in the abdomen noted since 1 month. The lump was noted by the patient's spouse and had not increased in size since the time it had been noted. There is no history of abdominal pain or fever or vomiting. He had normal bowel habits with no history of weight loss or change in appetite. No history of any medical or other surgical illness in the past and no history of addictions or allergies. He had been diagnosed with retroviral infection 3 years back.
On initial examination, his temperature was $38^{\circ} \mathrm{C}$, heart rate $74 / \mathrm{min}$, respiratory rate $18 / \mathrm{min}$, and blood pressure $118 / 80$ $\mathrm{mmHg}$.Patient was well built and nourished. On physical examination, his head and neck exam were within normal limits, and there was no lymph node enlargement. His chest was clear to auscultation, and no cardiac murmur was audible. Abdominal examination showed an abdominal mass that was hard in consistency and mobile; there was, however, no hepato-splenomegaly, no inguinal hernias, and no lymph node enlargement.

Scrotal examinations revealed a normal right testis and scrotum, whereas the left testis was neither palpable in the scrotum nor in the inguinal region. Clinical laboratory studies revealed a white blood count of $5200 \mathrm{cell} / \mathrm{mm}^{3}$, with $58 \%$ neutrophils, $31 \%$ lymphocytes, $10 \%$ monocytes, and $2 \%$ eosinophil; hemoglobin of $13 \mathrm{~g} / \mathrm{dL}$; and a platelet count of $300,000 / \mathrm{mm}^{3}$. Viral markers for $\mathrm{HCV}$ and $\mathrm{HCV}$ were negative; the aspartate aminotransferase was $30 \mathrm{IU} / \mathrm{L}$, and the alanine aminotransferase was $28 \mathrm{IU} / \mathrm{L}$. The erythrocyte sedimentation rate was $17 \mathrm{~mm} / \mathrm{h}$. Kidney function tests were within normal limits. His CD4 counts were 204 cells/microliter, CD4 \% was $16.25 \%$; His tumor markers : beta HCG- $26.96 \mathrm{mIU} / \mathrm{mL}$ (increased); alpha fetoprotein within normal limits; His HIV-I viral load was 40,490 copies per $\mathrm{mL}$.

In ultrasonographic scanning, a large, about $15 * 14 * 9.75 \mathrm{~cm}$ $\mathrm{cm}$ sized, well outlined, mildly vascular intra-abdominal mass was found. It is complemented with a CT scan observing moderate to large sized iso to hypodense soft tissue mass lesion in mid and lower abdomen in the midline and towards the right with no evidence of calcification. The lesion is seen receiving rich arterial blood supply from the branches of the right testicular artery; The lesion measures about $15 * 16^{*} 11 \mathrm{~cm}$ in size in maximum cranio-caudal, transverse and A-P diameter respectively. The lesion displaced the small and large bowel loops towards the periphery and is intraperitoneal. Enlarged retro-peritoneal peri-aortic lymph nodes and a few small lymph nodes in the aorto-caval aspect. Findings suggestive of undescended left testis with malignant mass lesion of the same, with 


\section{International Journal of Science and Research (IJSR) \\ ISSN (Online): 2319-7064}

Index Copernicus Value (2013): 6.14 | Impact Factor (2014): 5.611

metastatic retroperitoneal lymph node and mild ascites. Chest X-ray was normal.

Laparotomy was done through a transverse incision and the total excision of the tumor was carried out. The resection was performed without complications, and the postoperative period was uneventful. The pathological report revealed a classical seminoma of left testis.

\section{Discussion}

In humans, testes develop in the abdomen and normally descend into the lower portion of the scrotum during the third trimester. During the descent, it may be arrested anywhere along its tract (cryptorchidism) or may migrate into an abnormal position (ectopic testis). The most common sites of undescended testis are high scrotal (50\%), canalicular (20\%), and abdominal (10\%), bilateral $(10 \%) .1$ The cancer risk of an ectopic testis is 40 times higher in a normal testis. Furthermore, an abdominal testis is four times more likely to undergo malignant degeneration than an inguinal testis. ${ }^{2}$ The cancer of undescended testes usually peaks in the third or fourth decade of life. ${ }^{2}$

Tumor in an abdominal testis is more likely to be seminoma, but tumors in testes previously corrected by orchidopexy are more likely to be nonseminomas.

In ultrasonographic scanning, most GCTs (giant cell tumors) are solid, hypoechoic tumors. Cystic degeneration may be seen as representing necrosis and hemorrhage. CT and MRI show heterogenous soft tissue mass and retroperitoneal lymphadenopathy. CT shows calcifications better and MRI is superior in terms of detecting hemorrhage. Imaging and laboratory studies ( $\alpha$-FP and B-HCG) are quite useful in suggesting the diagnosis. Exploratory laparotomy and subsequent pathological examination are diagnostic too. 5

Undescended testes with intra-abdominal testes are more likely to be seminomas. Seminoma is a germ cell neoplasm of the testis. For this reason, testicular cancer should be considered as the differential diagnosis of an abdominal mass in patients with a non-palpable testis.

Two hypotheses have been proposed to explain this association. The first one posits that local temperature elevation of an ectopic testis is, somehow, procarcinogenic. If this hypothesis is true, then orchidopexy (testis descend and fixation in the scrotum) could protect against cancer if the procedure is performed before precancerous cells differentiate to a critical point such as that of puberty. The second hypothesis posits that an underlying hormonal condition predisposes to both cryptorchidism and testicular cancer. If so, orchidopexy would not prevent the testicular cancer; and orchidectomy would be required. ${ }^{2}$

A high intra-abdominal temperature has been incriminated as the cause of carcinogenesis in the testis. There may be a decrease in the spermatogenesis, Leydig cell abnormality, and delay in the development of the Sertoli cells in the testis, leading to infertility. ${ }^{6}$ In our case, there was no evidence of sterility due to the testicular malfunction and the patient had two children. Painless enlargement of the testis, or abdominal mass, is the common mode of manifestation in a cryptorchid testis. Rarely, an abdominal testicular tumor can cause an acute abdomen, a massive abdominal mass, pain, and hematuria because of adjacent visceral infiltration. ${ }^{6}$ Our patient had no such complications.

Various imaging modalities are available to diagnose and stage the condition. Classically, scrotal ultrasonography shows hypoechoic intratesticular mass in seminoma and at times with some calcification and cystic changes though mainly in non-seminomas. CT scanning of the abdomen and the pelvis is a very sensitive tool for the metastatic evaluation, which definitely helps plan the management. CT scan of the chest can usually be omitted unless there is an abnormal CXR finding. ${ }^{?}$

In developed countries, the existence of undescended testicles in the adult population is rare, which is due to systematic practice of elective orchidopexy before the second year of life to prevent cancer and infertility. Orchidopexy does not eliminate cancer risk but allows an early diagnosis by making testicles accessible to exploration. ${ }^{\underline{3}}$

In conclusion, despite the elevated risk of testicular cancer in patients with intra-abdominal testicles, it is still a low incidence disease. This could be due to standard practice of orchidopexy in pre-adolescent patients and orchiectomy in post-adolescents ones with cryptorchidism. Nevertheless, there are still some cases of intra-abdominal testicle tumors, which could presumably be avoided with the adoption of adequate prevention strategies.

\section{References}

[1] Dahnert W. Radiology review manual. 5th ed. Williams and Wilkins; 2003. Testicular tumor; p. 925.

[2] Alshyarba MH. A giant intra-abdominal testicular seminoma. Biomed Res. 2010;21(3):227-229.

[3] Cristián Palma C, Cristóbal B, Maccioni R. Seminoma in an adult cryptorchid testis (intra-abdominal): a case report. Actas Urol Esp. 2007;31(2):160-163. [PubMed]

[4] Shrestha B, Baidya JL. Unresolved abdominal mass. Kathmandu Univer Med J. 2009;7(25):82-85. [PubMed]

[5] Chandrasekharan LV, Abdl Ghaffar T, Venkatramana M, Rath S. A case of teratocarcinoma. Internet $\mathrm{J}$ Radiol. 2005;4(1) In: Abdominal testis: a case report. Available from:

http://www.ispub.com/journal/the_internet_journal_of_ra diology/volume_4_number_1_46/article/a_case_of_terat ocarcinoma_in_abdominal_testis_a_case_report.html. Accessed $1 \overline{6}$ Nov, 2010.

[6] Haque MM, Siddique AB, Rabbani ABMG, Quasem MA, Rahman AKMG, Rahman MM. Seminoma in undescended intra abdominal testis: a case report. TAJ: Journal of Teachers Association. 2005;18(2):131-133.

[7] Joseph C, Presti JR. Genital tumours. In: Tanagho EA, McAninch JW, editors. Smith's general urology. 17th ed. New York, NY: Lange Medical Books/McGraw-Hill, Medical Publishing Division; 2008. pp. 375-382. 
International Journal of Science and Research (IJSR)

ISSN (Online): 2319-7064

Index Copernicus Value (2013): 6.14 | Impact Factor (2014): 5.611

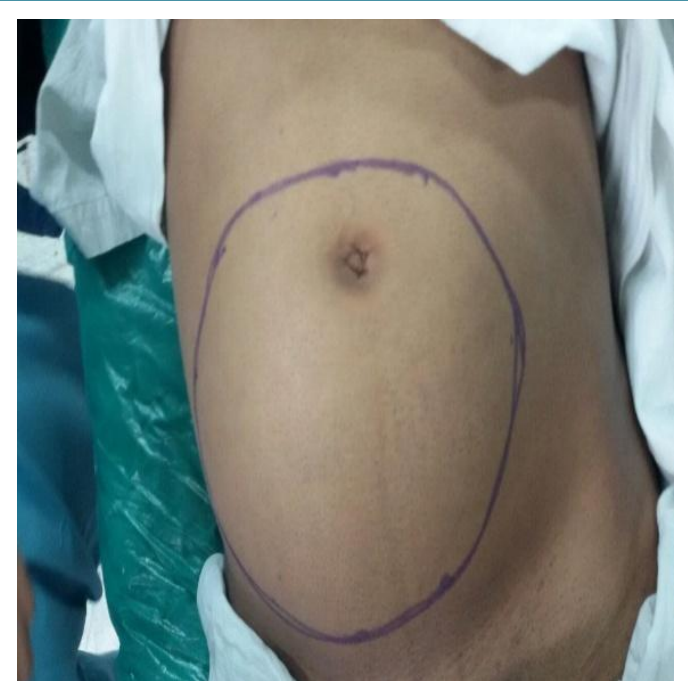

Surface marking of the margins of the tumor

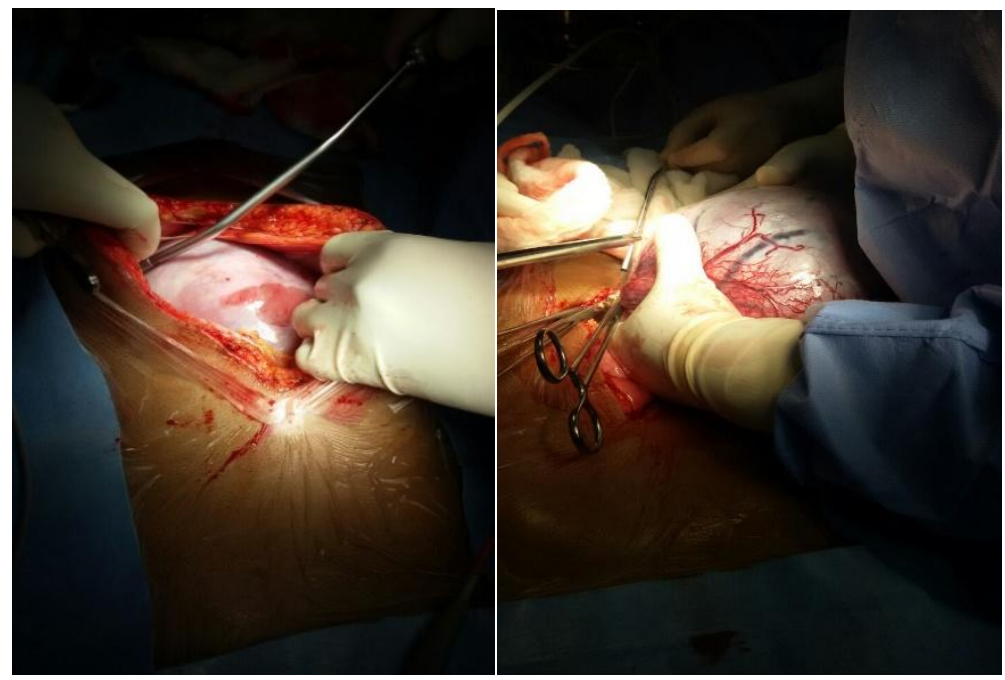

Intra-operative photos of the testicular tumor mass being excised.

Volume 4 Issue 12, December 2015

www.ijsr.net 